\title{
The Implication of Analysis Module on Vehicle Bridge Interaction Modelling
}

\author{
Ahmed Elhattab ${ }^{1 *}$ and Nasim Uddin ${ }^{2}$ \\ Department of Civil and Environmental Engineering, University of Alabama, Birmingham
}

Submission: September 14, 2017; Published: December 11, 2017

*Corresponding author: Ahmed Elhattab, The University of Alabama at Birmingham, 1075 13th St. S, Birmingham, AL 35205, Tel: 205-447-2127;

Email: aahattab@uab.edu

\begin{abstract}
Bridge structures are susceptible to devastating failures ascribing to the continuous strength reduction over time, as well as the unprecedented increase in freight volumes. Therefore, understanding the dynamic response of bridges due to moving traffic, specifically heavy trucks, has attracted the interest of the highway engineers. To this end, Vehicle Bridge Interaction (VBI) modelling has been adopted as a reliable and effective approach to mimic bridge vibrations under transit traffic. The decoupled VBI modelling is based upon solving the vehicle and the bridge equations of motion separately, by equating the contact forces between the vehicle and the bridge at each time step. The equations of motion can be solved either implicitly or explicitly. Implicit analysis directly solves for the displacement vector $\{\mathrm{x}\}$, which consequently requires calculation of inverse of stiffness matrix. Whilst explicit analysis solves for the acceleration vector $\{\mathrm{x}\}$ by inverting the mass matrix. Most of VBI algorithms adopt an implicit solver, however, the implicit analysis is adequate to simulate static and quasi-static responses which is not representative of the dynamic nature of the truck and bridge vibrations in the field. This article is devoted to illuminate the difference between explicit and implicit solvers in modelling the VBI problems. The implicit modelling was implemented in MATLAB, while the explicit solution was performed using LS- Dyna FEA program. The study pay off is to high light the implication of the solver module on the modelling results which could be essential for some applications specifically when the faint changes in the bridge responses are of interest, such as Bridge Health Monitoring and Drive-by Bridge Inspection applications.
\end{abstract}

\section{Introduction}

The degradation in the structural integrity of the highway bridges is ascribing to ageing and the dramatic increase in freight volumes. In the United States, approximately $11 \%$ of the bridges on the transport network has been classified as structurally defective $[1,2]$. Therefore, bridge safety assessment under operational traffic weight has become an essential area of research [3-5]. To this end, it is imperative to depict the bridge attribute (real time vibration) under the weight of passing vehicles [6,7]. To simulate the vehicle bridge interaction, one of the following approaches can be adopted [6,7],

a. Decoupling the vehicle and the bridge equation of motions and solving their equations independently by equating the contact forces between the vehicle and the bridge in an iterative procedure $[8,9]$, or

b. To couple the vehicle and the bridge equation of motions by eliminating the contact force from their equations and having one system matrix includes the vehicle and the bridge properties $[10,11]$. These concepts are based upon achieving equilibrium of forces and compatibility of displacements at the point of contact between the vehicle and the bridge during the simulation time. In short, either of these concepts can be followed to link the vehicle and the bridge equations of motion as depicted in (Figure 1). The resulted equations represent the Vehicle Bridge Interaction (VBI) system. The equations of motion in the VBI system can be either solved implicitly or explicitly as previously noted. Implicit analysis, which is widely used in civil engineering applications, is based upon solving the displacement vector $\{x\}$, then calculate its derivative to estimate the velocity and the acceleration. Consequently, it requires inverting the system stiffness matrix which is often a complex procedure and in some cases requires a numerical solver to invert the matrix once or even several times over the time step. On the other hand, the analysis is unconditionally stable and is independent of the size of the time step [8,12]. In another vein, the explicit analysis solves the acceleration vector $\left\{\mathrm{x}^{\prime \prime}\right\}$ rather than the displacement vector $\{\mathrm{x}\}$, hence it is accompanied with inverting the diagonal mass matrix. Therefore, the inversion step in the explicit analysis is not an expensive operation, however, the time step must be less than the Courant step (time it takes a sound wave to travel across an element), which results in a discrete time step. Explicit analysis manifests in highly transit dynamic analysis, 
such as explosions, impact and crash analysis. Vehicle Bridge Interaction modelling can be classified as highly transit dynamic problem, unlike other civil structures, where a massive dynamic load used to traverse the bridge in a fraction of a second (e.g. a vehicle travelling with $27 \mathrm{~m} / \mathrm{s}$ [60mph] will cross a $10 \mathrm{~m}$ bridge in $0.37 \mathrm{sec}$ ). Accurate representation for the bridge vibration is imperative for bridge Health Monitoring applications, especially that SHM techniques rely on observing the anomalies in the structure response which are associated to the presence of damage $[5,13]$. This article highlights the effect of the analysis technique on the vehicle and the bridge responses. The implicit analysis has been carried out using MATLAB VBI algorithm [14-16]. Whilst, the explicit modelling of the VBI problem has been performed with the aid of LS-Dyna FE program. The goal of this article is to discuss the plausibility of using implicit analysis to solve the VBI problem, specifically for Bridge Health Monitoring applications.

\section{Vehicle and Bridge Properties}

The vehicle has been modelled as a quarter car with two degrees of freedom, the axle mass and body mass translations. The vehicle model is shown in Figure 1 and its properties are based on the works of Cebon [17] and Harris, 0 Brien and González [18]. A 15-m bridge will be utilized in this study. The bridge properties are shown in Error! Reference source not found.

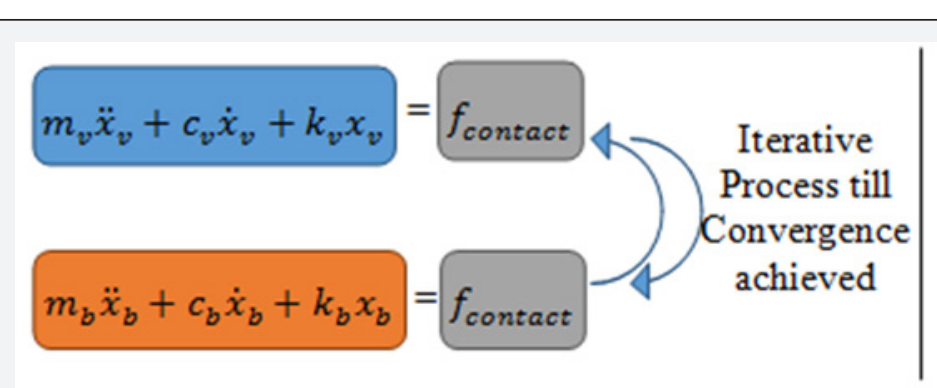

(a) Approach "a"
Coupled System

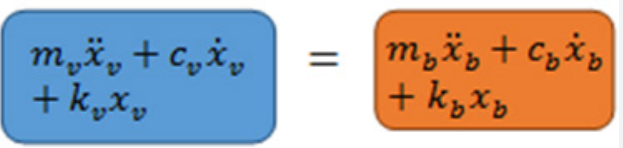

Figure 1: Difference between the two approaches adopted for modeling the VBI system.

\section{Comparison between Implicit and Explicit Solvers} Results

The quarter car model has been simulated crossing the $10-\mathrm{m}$ bridge, and the analysis has been carried out twice using explicit and implicit analysis (Figure 2) (Table 1). Figure 3 illustrates the results of the mid-span acceleration, the Quarter-car axle mass acceleration history and the displacement under the passing quarter car for the two modules. The first point of note, is that there is a dramatic difference between the two attributes. The amplitude of the responses (i.e. for all the figures) are closely matched, however, the response shape is completely different. First, explicit module showed two bouncing in the displacement history (Figure 3a), while the implicit analysis shows an attribute close to the static responses of the bridge. The results are deemed to be compelling with the nature of the implicit and explicit solvers. The implicit solver is adequate to represent low-frequency vibration responses, this clearly depicted in the bridge displacement which tends to be static. On the other hand, the discrete time step of the explicit analysis allows capturing the incremental changes in the bridge vibration over the sample time. Similar behaviours are found for the acceleration of the bridge midpoint (Table 2). Figure 3b \& 3 C shows that implicit solver gives a pure sinusoidal signal, while the explicit solver shows some perturbation around the mean value. The quartercar responses are shown to be similar, yet still not identical for the two cases.



Figure 2: Theoretical quarter car model.

Table 1: Properties of the quarter car model.

\begin{tabular}{|c|c|c|c|}
\hline Property & Unit & Symbol & Value \\
\hline Body Mass & $\mathrm{kg}$ & $\mathrm{mb}$ & 17300 \\
\hline Axle Mass & $\mathrm{kg}$ & $\mathrm{ms}$ & 700 \\
\hline Body Stiffness & $\mathrm{N} / \mathrm{m}$ & $\mathrm{kb}$ & $4 \times 105$ \\
\hline Body Damping & $\mathrm{N} . \mathrm{s} / \mathrm{m}$ & $\mathrm{cb}$ & $10 \times 103$ \\
\hline $\begin{array}{c}\text { Suspension } \\
\text { Stiffness }\end{array}$ & $\mathrm{N} / \mathrm{m}$ & $\mathrm{ks}$ & $1.75 \times 106$ \\
\hline $\begin{array}{c}\text { Body Bounce } \\
\text { Frequency }\end{array}$ & $\mathrm{Hz}$ & fbounce & 0.69 \\
\hline $\begin{array}{c}\text { Axle Hop } \\
\text { Frequency }\end{array}$ & $\mathrm{Hz}$ & faxle & 8.8 \\
\hline
\end{tabular}




\section{Civil Engineering Research Journal}

Table 2: Properties of the bridge.

\begin{tabular}{|c|c|c|}
\hline Property & Unit & Value \\
\hline Length & $\mathrm{m}$ & 4945 \\
\hline Mass per unit length & $\mathrm{kg} / \mathrm{m}$ & 35000 \\
\hline Elastic Modulus & $\mathrm{MPa}$ & 0.044 \\
\hline Second Moment of area & $\mathrm{m} 4$ & 8.83 \\
\hline $1^{\text {st }}$ Frequency & $\mathrm{Hz}$ & 35.32 \\
\hline $2^{\text {nd }}$ Frequency & $\mathrm{Hz}$ & 79.48 \\
\hline $3^{\text {rd }}$ Frequency & $\mathrm{Hz}$ & \\
\hline
\end{tabular}

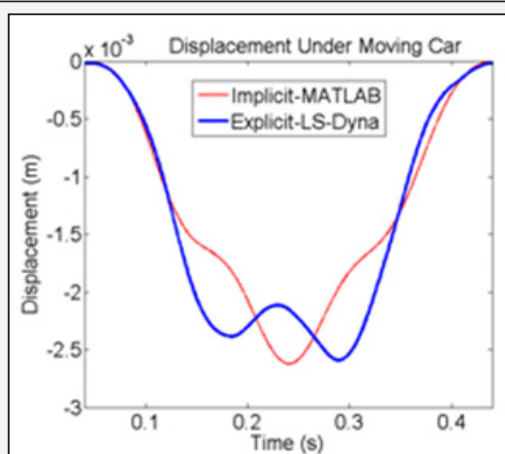

(a)

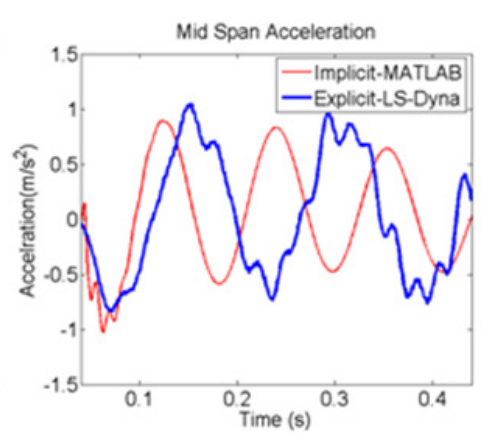

(b)

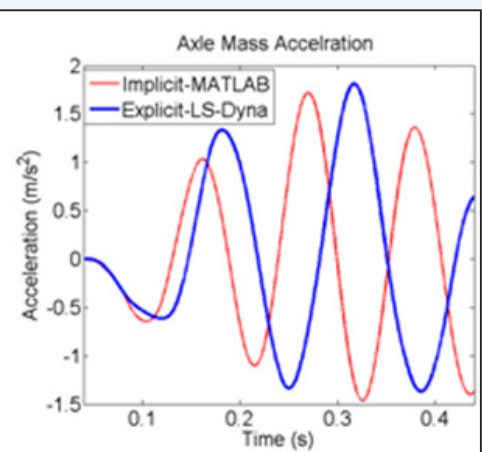

(c)

Figure 3: Difference between the two approaches adopted for modeling the VBI system.

\section{Conclusion}

This article high lights the difference between implicit and explicit analysis in simulating Vehicle Bridge Interaction problems. The authors presume that explicit analysis is preferable for modelling VBI problems. The small size of the step allows for municipal vibrations to be depicted for each point along the bridge. This is essential for bridge health monitoring applications since those techniques are based upon tracking the changes in the bridge responses due to the presence of damages. The results listed in this article showed the dramatic difference between the two solvers, which requires further investigation to ascertain the solver's suitability for vehicle bridge interactions modelling.

\section{Acknowledgement}

The authors wish to express their gratitude for the financial support received from the National Science of Foundation (NSFCNS-1645863). Any opinions, findings, and conclusions or recommendations expressed in this publication are those of the authors and do not necessarily reflect the view of the sponsors.

\section{References}

1. Davis SL, Goldberg D, De Good K, Donohue N, Corless J (2013) The Fix We're In For: The State of our Nation's Bridges. Transpiration of America, USA.

2. FHWA (2017) Status of the Nation's Highways Bridges and Transit: Conditions and Performance. Federal Highway Administration, USA.

3. Yang Y, Chang K (2009) Extracting the bridge frequencies indirectly from a passing vehicle: Parametric study. Engineering Structures 31: 2448-2459.
4. Malekjafarian A, Mc Getrick PJ, Obrien EJ (2015) A review of indirect bridge monitoring using passing vehicles. Shock and Vibration.

5. Elhattab A, Uddin N (2017) Drive-by Bridge Damage Monitoring: Concise Review Civil Engineering Research Journal 1: 1-6.

6. González A (2010) Vehicle-bridge dynamic interaction using finite element modelling. Finite element analysis In Tech.

7. Yang YB, YauJ J, Yao Z, Wu Y (2004) Vehicle-bridge interaction dynamics: with applications to high-speed railways. World Scientific, Taiwan.

8. Zhu X, Law S (2002) Dynamic load on continuous multi-lane bridge deck from moving vehicles. Journal of Sound and Vibration 251: 697716.

9. Cantero D, O’Brien EJ, González A (2010) Modelling the vehicle in vehicle-infrastructure dynamic interaction studies, Proceedings of the Institution of Mechanical Engineers. Part K: Journal of Multi-body Dynamics 224: 243-248.

10. Moghimi H, Ronagh HR (2008) Impact factors for a composite steel bridge using non-linear dynamic simulation. International Journal of Impact Engineering 35: 1228-1243.

11. Deng L, Cai C (2010) Development of dynamic impact factor for performance evaluation of existing multi-girder concrete bridges. Engineering Structures 32: 21-31.

12. Kim CW, Kawatani M, Kim KB (2005) Three-dimensional dynamic analysis for bridge - vehicle interaction with roadway roughness. Computers \& structures 83: 1627-1645.

13. Carden EP, Fanning P (2004) Vibration based condition monitoring: a review, Structural health monitoring 3: 355-377.

14. El-hattab A, Uddin N, Obrien E (2015) Drive by Bridge Damage Detection Using Apparent Profile, First International Conference on Advances in Civil Infrastructure and Construction Materials (CISM), Bangladesh p. 33-45. 


\section{Civil Engineering Research Journal}

15. ElHattab A, Uddin N, Obrien E (2017) Drive-by bridge damage detection using non-specialized instrumented vehicle Bridge Structures 12: 7384.

16. Elhattab A, Uddin N, Obrien E (2016) Drive-by bridge damage monitoring using Bridge Displacement Profile Difference, Journal of Civil Structural Health Monitoring 6: 839-850.
17. Cebon D (1999) Handbook of vehicle-road interaction ALWAYS.

18. Harris NK, Obrien EJ (2007) González A Reduction of bridge dynamic amplification through adjustment of vehicle suspension damping. Journal of Sound and Vibration 302: 471-485.



This work is licensed under Creative

Commons Attribution 4.0 License

DOI: 10.19080/CERJ.2017.02.555600
Your next submission with Juniper Publishers will reach you the below assets

- Quality Editorial service

- Swift Peer Review

- Reprints availability

- E-prints Service

- Manuscript Podcast for convenient understanding

- Global attainment for your research

- Manuscript accessibility in different formats

( Pdf, E-pub, Full Text, Audio)

- Unceasing customer service

Track the below URL for one-step submission https://juniperpublishers.com/online-submission.php 